\title{
Prosthetics in Leprosy ${ }^{*}$
}

\author{
RONALD J. GARST \\ Associate Professor of Orthopaedics, Christian Medical College, \\ Ludhiana, Punjab, India
}

\begin{abstract}
This paper deals with the implications for amputation of the lower extremity of the patient with Hansen's disease, the preparation of the prosthesis, and the care of the stump. Particular attention is given to the making of a hard socket to prevent breakdown of the skin of the stump. Inexpensive methods of producing useful and acceptable prostheses are described.
\end{abstract}

\section{Introduction}

The management of amputees suffering from leprosy (Hansen's disease) offers a fascinating challenge to the prosthetist as well as to the orthopaedist who does the amputation and follows the care and fitting of the stump. The knowledge gained and practised regarding patients with Hansen's disease can be carried over into use for any amputee with sensory paralysis of the lower extremities. This is especially true in the case of paraplegia and spina bifida.

As an orthopaedist I will not try to tell the prosthetist how to make an artificial limb. However, there are a few points that we have observed which may be of help, or which may stimulate further study. One of the best monographs on the subject of orthopaedic and prosthetic appliances for leprosy is that written by J. A. E. Gleave, published by the United Nations Organization (Gleave, 1968). Most workers devise their own short cuts and simplifications, but all have not been published. By far the majority of leprosy patients in India who have undergone amputation go without the benefit of prostheses. Some of the reasons are the cost, the lack of prosthetic facilities available, unsatisfactory fitting followed by rejection of the limb, and the psychology of a begging community who get more alms by displaying grotesque deformities-the amputee leaves his prothesis at home when he goes out to beg. In this paper we will deal with our management of some of these difficulties.

\section{Pathology}

Any type of leprosy may result in loss of sensation, and the problem of fitting a prosthesis is the same. The loss of sensation creates a host of problems, such as

\footnotetext{
* Received for publication 19 October, 1970.

$\dagger$ This study was partly sponsored by the Social and Rehabilitation Service, U.S. Department of Health Education and Welfare.
} 
ulceration due to trauma and pressure. The ulcer gradually becomes deeper and involves the bone and joint, causing an osteomyelitis or septic arthritis. The disease may also cause cystic areas in the small bones of the extremities with resulting collapse and deformity (Job, 1963; Lechat, 1962; Paterson, 1961). Finally the loss of sensation in the joint may produce a Charcot-type joint which gradually disintegrates and becomes literally a "bag of bones". The unhappy plight of the leprosy patient in India contributes to his neglect of his wound (Figs 1,2). The infection which follows may destroy the extremity so that it cannot be salvaged. The orthopaedist's primary rôle is to prevent complications arising from the involved extremity. Many papers and monographs (Fisher, 1955; Girling et al., 1967; Walkey et al., 1965) have been written on the care of the feet for healing of the ulcers with proper footwear. Where the main problem is motor paralysis corrective surgery by tendon transfers, arthrodeses, and/or bracing are very satisfactory, both in the feet as well as the hands (Fritschi and Brand, 1957).

When the condition has progressed beyond the stage of a cure of the ulcer and the infection of bones and joints, then amputation must be resorted to. It is our policy to do the least amputation possible. The general principles of avoiding the Chopart amputation (Fig. 3), and amputation through the lower third of the tibia are generally adhered to. Toes may be removed and we are sometimes amazed to see how many years a patient will walk around on a mid-tarsal or Chopart-type stump.

The rest of this discussion will be devoted to our findings with the Syme's and more proximal amputations.

\section{Methods}

\section{SYME'S AMPUTATION}

Wherever possible, if the foot has to be amputated, a Syme's amputation is done. Good normal skin under the calcaneum is a prerequisite for this procedure. We have found, however, nearly as much difficulty in providing a prosthesis for this type of stump as for a below-knee amputation. Because of this, we insist on a very carefully fitted patellar tendon-bearing prosthesis, distributing the weight as evenly as possible over the patellar tendon, the upper part of the leg, and the end of the stump itself. Any spurs that develop under the end of the stump will predispose to ulceration. Pressure on any scar or this portion of skin of the leg must be avoided.

\section{BELOW-KNEE AMPUTATION}

Whenever possible, the usual below-knee amputation is performed, leaving a stump 5 to 6 in $(12.5$ to $15 \mathrm{~cm})$ long. An attempt is made to get a synostosis formed between the distal end of the tibia and fibula, as this gives a more stable stump. Immediate-fitted prostheses have occasionally been used, although in the event of pre-existing infection this usually cannot be done. The immediate-fitted prosthesis has not been very successful in our hands, owing to the breakdown of anaesthetic skin. We strongly feel that wherever possible, the knee-joint should be saved as a bent knee; end-bearing prosthesis may be provided. Even when the stump is too short for a patellar-tendon-bearing prosthesis, a good weight-bearing 


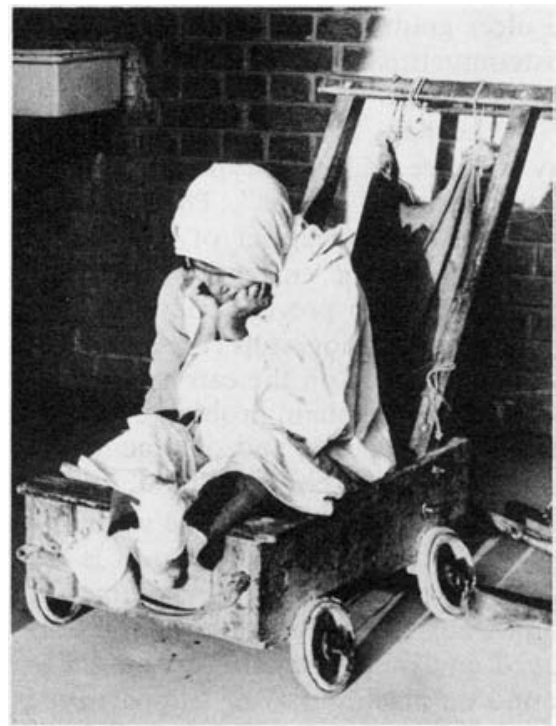

Fig. 1.

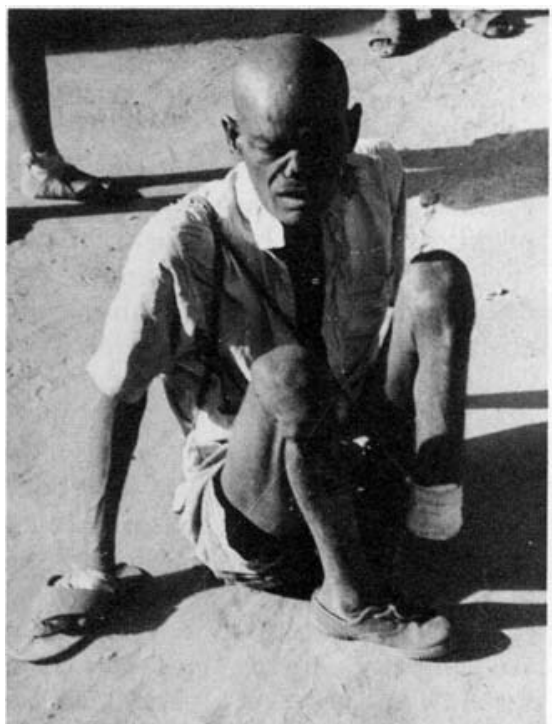

Fig. 2.

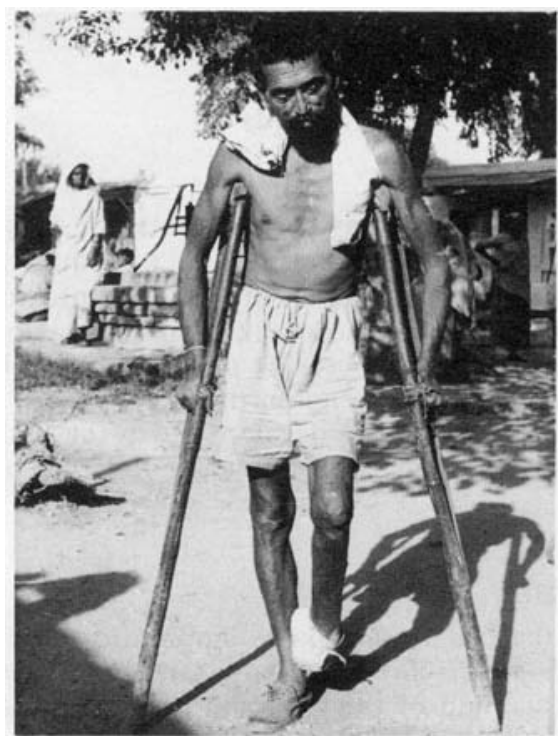

Fig. 3.

Fig. 1. The leprosy patient's unhappy plight.

Fig. 2. An artificial limb would enable this man to walk.

Fig. 3. Chopart-type amputation with resultant deformity (note left hand tied to crutch.) 
surface remains. The only prerequisites are that the patellar tendon with the tubercle be intact and the skin healthy. Through-knee or standard above-knee amputations may also be used.

\section{PREPARATION OF THE PROSTHESIS}

The initial step in the preparation of the prosthesis is a thorough examination of the skin and stump for pathological changes, oedema, and other symptoms (MacGregor, 1962; Pfaltzgraff, 1963). Only when it is ascertained that there are not apparent conditions that will lead to breakdown of the skin later on, is work on the socket begun. The patellar-tendon-bearing socket (Ross, 1963) is used in our institution whenever possible. The main departure from it that we are studying, and which we wish to present here, is the use of the hard socket instead of the soft socket. Our reasons for this are as follows: A collection of moisture next to the skin of any patient with total anaesthesia, such as paraplegics and leprosy patients, predisposes to breakdown of the area. For example, a rubber macintosh under the sheet on which a paraplegic is lying will generate heat, causing a collection of moisture and the breakdown of the skin into decubitus ulcers. Rubber and leather lining in a soft socket creates an ideal environment for the collection of moisture and the breakdown of the skin of the stump. The one exception is microcellular rubber used for the "chapple" or shoe of the patient with leprosy. This is acceptable because there is no problem of the collection of moisture on the surface and the sole of the foot is the normal weight-bearing area of the body. The hard socket is similar to the walking-boot cast which is generally accepted as the treatment of choice for ulcers on the plantar surface of the foot of a leprosy patient. In the preparation of this cast, no lining is used under the plaster. A small amount of sheet wadding or cotton and stockingette are all that are needed. Following this principle in the making of the socket for the prosthesis, we make a plastic socket with no lining other than the patient's stump sock. We feel that this hard socket will prove ideal for the patient with leprosy, especially if a porous plaster is used or a few holes are drilled in the socket (Fig. 4).

\section{END-BEARING PROSTHESIS}

When the stump is too short, or in too poor a condition, or when the patient has a fixed contracture, a patellar-tendon-bearing prosthesis is not practical. In these cases a simple end-bearing prosthesis can easily be made with a leather bucket and ordinary hinge-joint for the knee (Fig. 5). The patient starts right off walking when this is applied as it affords good control. Full pressure can usually be put on the end of the stump without fear, as usually there is no anaesthesia over the knee and patellar tendon itself.

\section{ABOVE-KNEE PROSTHESIS}

Where through-knee or above-knee amputations have been carried out the usual fitting, as in any other above-knee type, may be done. For our above-knee prostheses we use total contact quadrilateral plastic sockets with a belt. There is no vacuum for suction, and the patient wears one or 2 stump socks. 


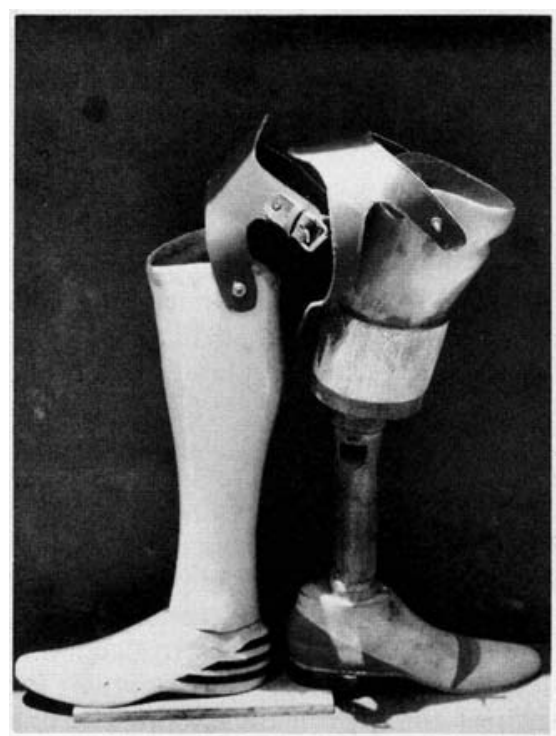

Fig. 4.

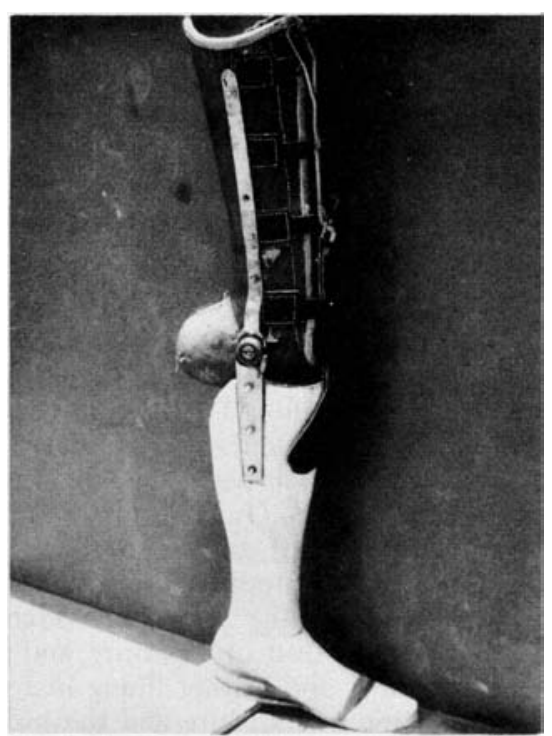

Fig. 5. feet.

Fig. 4. Hard socket. Foort-type alignment shin. Rubber and wooden solid-ankle-cushion-heel

Fig. 5. Knees bearing prosthesis before finishing.

\section{COSTS}

One of the major problems in providing an artificial limb for the leprosy patient is that neither the patient himself nor the sponsoring agent can afford the cost of supply. Keeping this in mind, we have the following suggestions to make:

(1) Plastic. We have had good results with the polyester resins. They are generally much cheaper than epoxy resins. In our institution the cost of plastic for a below-knee prosthesis is about $\$ 2.00$. Technicians can be trained in a much shorter time to use plastics than is required when only wood is used.

(2) Wood. With the use of plastic prostheses, wood does not play the important rôle that it did in the older type of prostheses. Any light wood of the area can be used.

(3) Shin. We have recently been making a Foort-type shin assembly (Foort and Hobson, 1965; Radcliff and Foort, 1961) with wedged discs entirely out of bamboo (Fig. 6). The cost of this item is negligible.

(4) Bicycle knee joints. In searching for a knee-joint of good quality steel, we found that the front hub of a bicycle is the average size for an adult knee. It comes complete with axle, ball bearing, etc., of very good steel. The cost is 56 cents in our area. This joint with a simple platform and a pipe for the shin (Figs 8,9 and 10) fastened to the foot, gives an above-knee prosthesis that can be easily aligned. This is covered with a very thin shell of plastic for below the knee, and the usual plastic covering above the knee. The bicycle hub can also be inserted into a shaped knee block (Fig. 8). (Named after Barkat Masih, our prosthetist who designed the block.) 


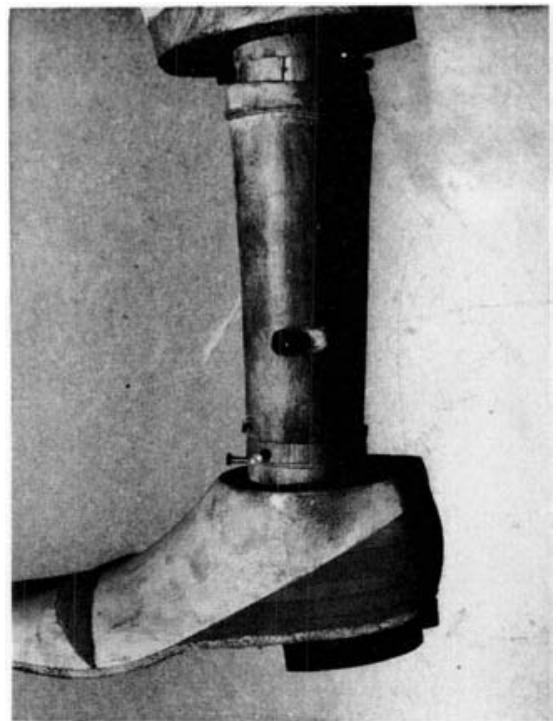

Fig. 6.

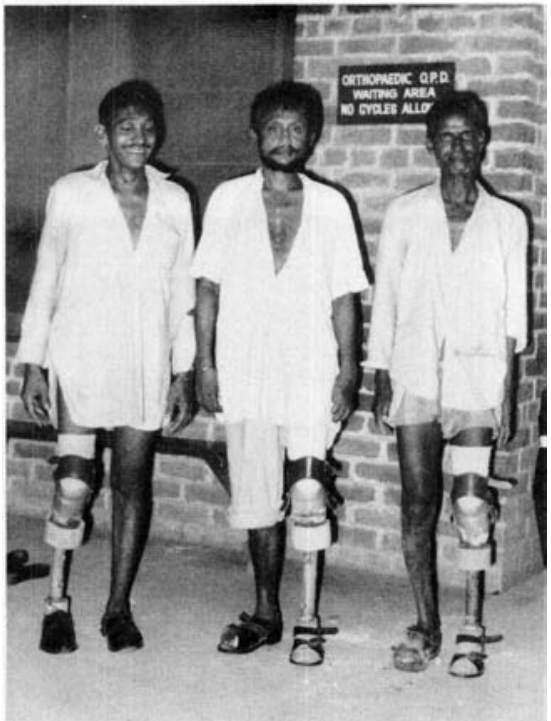

Fig. 7.

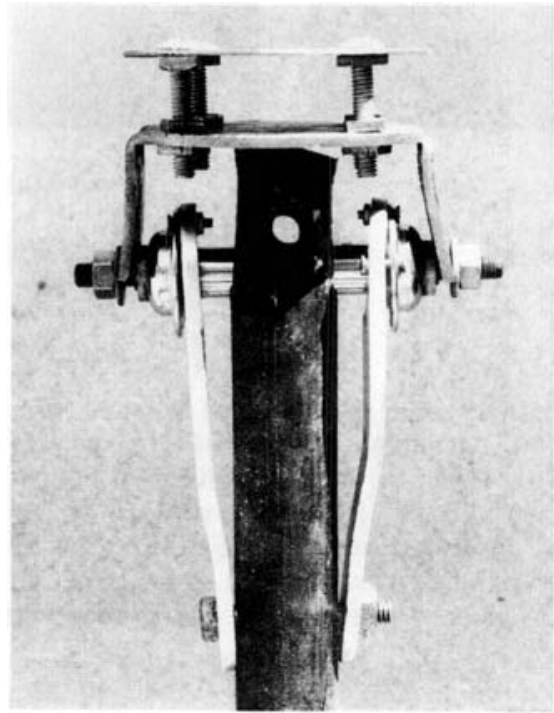

Fig. 8 .

Fig. 6. Foort-type shin, using bamboo. Wooden type solid-ankle-cushion-heel foot.

Fig. 7. Three limbs on trial using Foort-type bamboo shin.

Fig. 8. Knee joint using front hub of bicycle and alignment platform. 
5. Foot. We use the cobbler's shoe form to make a solid-ankle-cushion-heel foot. We insert rubber for the toe break and make a rubber heel as in the conventional solid-ankle-cushion-heel foot (Fig. 9). This again is very inexpensive and eliminates the problem of the solid-ankle-cushion-heel feet made of inferior rubber which frequently fractures.

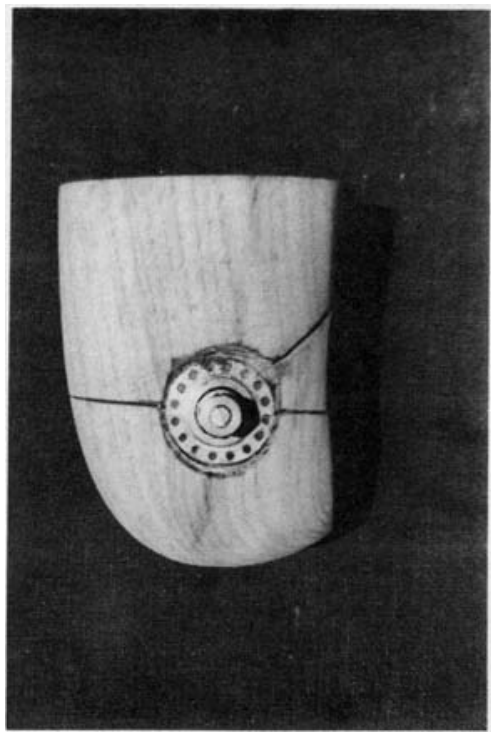

(a)

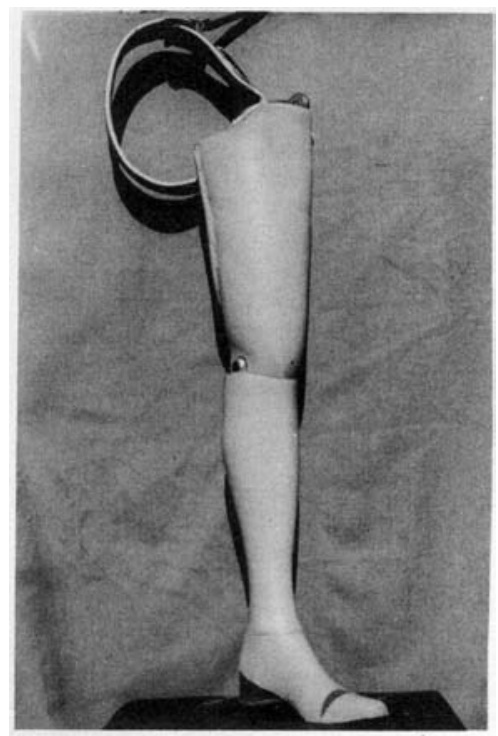

(b)

Fig. 9. (a) Barkat knee joint, using bicycle hub in knee joint. (b) Completed limb using bicycle knee.

The use of these simplified materials do not detract from the function of the prostheses and yet provide very inexpensive ones. In our area the cost amounts to about $\$ 10.00$ to $\$ 13.00$ ( $£ 4$ to $£ 5$ ) for either a below-knee or above-knee prosthesis, complete with foot. Everyone prefers to look normal and the application of a foot as described here adds $\$ 2.00$ or less to the cost of the limb. Any sort of a chapple or shoe can be used (Fig. 10). On occasion a rounded wooden block is used in place of a foot, but this is more difficult to align and is also unsightly.

\section{CARE OF THE STUMP}

It should be pointed out that more than the usual care must be given to the stump. The skin, the stump sock, and the socket must be absolutely clean. Any redness means that the prosthesis should immediately be removed and not used until the skin is healed and any defect in the socket has been corrected (Ross, 1963). 


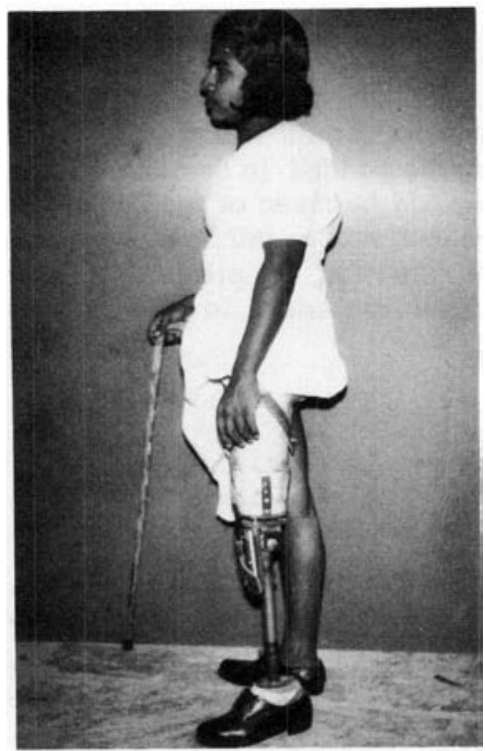

Fig. 10.

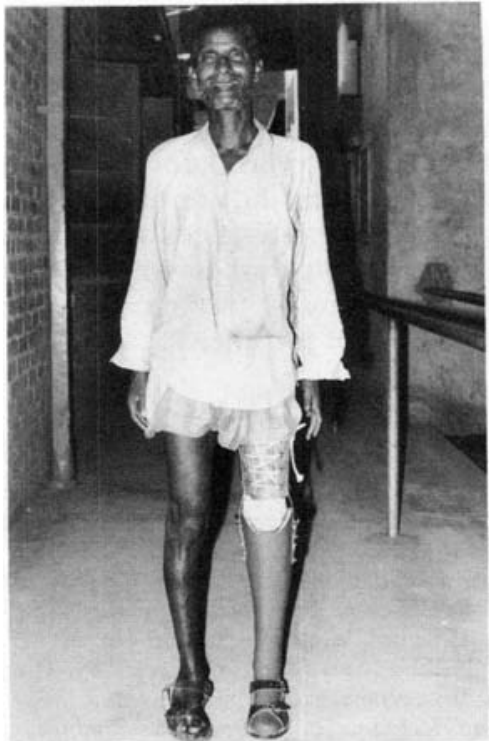

Fig. 12.

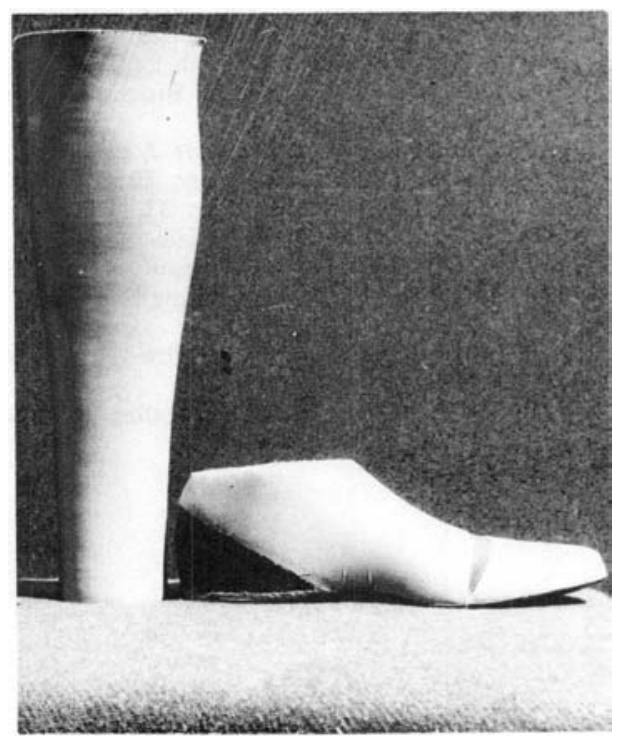

Fig. 11 .

Fig. 10. Bicycle knee joint on trial.

Fig. 11. Plastic shell for shin. Wooden foot solid-ankle-cushion-heel type covered with plastic.

Fig. 12. A leprosy patient walks out. Note chapple of microcellular rubber on right. 


\section{Conclusion}

Careful amputation should be carried out on the patients suffering from Hansen's disease. Application of a prosthesis requires careful fitting. Any factor that might lead to breakdown of the stump should be avoided. In certain climates, such as extremely hot or humid areas, studies should be made of the use of the hard socket in preference to the sof t socket lined with rubber and leather. As cost is always a factor, wherever leprosy patients are cared for, the prosthetic centre should continually search for inexpensive local materials to use in the manufacture of prostheses.

\section{References}

American Academy of Orthopedic Surgeons, Inc. (1952). Orthopedic Appliances Atlas, Vol 1. Fisher, C. (1955). Experiences with the treatment of trophic ulcers by plaster casts. Lepr. Rev. 26, 107.

Foort, J. and Hobson, D. A. (1965). A pylon prosthesis system for Shank (BK) Amputees. Prosthetics and Orthotics Research and Development Unit, Manitoba Rehabilitation Hospital, Winnipeg, Report No. 6.

Fritschi, E. P. and Brand, P. W. (1957). The place of reconstructive surgery in the prevention of foot ulceration in leprosy. Int. J. Lepr. 25, 26.

Girling, J., Mamead, M. D. and Selvapandian, A. J. (1967). Notes on Ulcer Preventive Footwear. Brochure, Christian Medical College and Hospital, Vellore, South India.

Gleave, J. A. E. (1968). Basic Services and Equipment for Rehabilitation Centres. Part VI. Orthopaedic and Prosthetic Appliances and Orthopaedic Footwear for Leprosy, Department of Economic and Social Affairs of the United Nations.

Gupta, M. L. (1900). Study of Orthopaedic Problems in Leprosy and Value of Split-sublimus Tendon Transplant in Post-lepra Claw Hands. Brochure from the Medical College, Pondicherry, South India.

Job, C. K. (1963). Pathology of leprous osteomyelitis. Int. J. Lepr. 31, 26.

Lechat, M. F. (1962). Bone lesions in leprosy. Int. J. Lepr. 30, 125.

MacGregor, H. (1962). Artificial limb making. Lepr. Rev. 33, 265.

Paterson, D. E. (1961). Bone changes in leprosy. Int. J. Lepr. 29, 265.

Pfaltzgraff, R. E. (1963). A prosthesis for below-knee amputees. Lepr. Rev. 34, 8.

Radcliffe and Foort (1961). The Patellar Tendon Bearing Prosthesis. Brochure, University of California, Berkeley.

Ross, W. F. (1963). Report on the patellar tendon below-knee prosthesis project Oji River Settlement. Lepr. Rev. 34, 151.

Walkey, G. B. R. and Williams, H.W. (1965). The rapid healing of plantar ulcers. Lepr. Rev. 36, 83. 